\title{
Exploring public bus service quality in South Africa: A structural equation modelling approach
}

\begin{abstract}
Authors:
Ayanda M. Vilakazi ${ }^{1}$

Krishna K. Govender ${ }^{2,3}$

Affiliations:

${ }^{1}$ Graduate School of Business, University of KwaZulu-Natal, South Africa

${ }^{2}$ School of Management, IT and Governance, University of KwaZulu-Natal,

South Africa

${ }^{3}$ Regenesys Business School, University of KwaZulu-Natal,
\end{abstract} South Africa

\section{Correspondence to:} Krishna Govender

Email:

krishnag@regenesys.co.za

Postal address:

Private Bag X9976, Sandton

City 2146, South Africa

Dates:

Received: 25 Oct. 2013

Accepted: 24 Mar. 2014

Published: 30 July 2014

How to cite this article: Vilakazi, A.M. \& Govender, K.K., 2014, 'Exploring public bus service quality in South Africa: A structural equation modelling approach', Journa of Transport and Supply Chain Management 8(1), Art. \#127, 10 pages. http:// dx/doi.org/10.4102/jtscm. v8i1.127

\section{Copyright:}

(C) 2014. The Authors.

Licensee: AOSIS

OpenJournals. This work

is licensed under the

Creative Commons

Attribution License.
This study, which is a deviation from the usual practice of using SERVQUAL or an adapted version thereof, uses McKnight, Pagano and Paaswell's (1986) service quality dimensions, namely reliability; extent of service; comfort; safety; and affordability (RECSA) and structural equation modelling to determine commuters' perception of public bus service quality in a major city in South Africa. The RECSA model was adapted and fitted to the data collected from a convenience sample of bus commuters in Johannesburg, using structural equation modelling. It was ascertained that reliability, service, comfort and safety influenced the public bus commuters' perception of the overall service quality. The implications of the aforementioned findings for providers of public bus services are explained.

\section{Introduction}

According to Finn and Mulley (2011:90), the mobility of people is fundamental to their ability to participate in society. In developed countries, mobility in urban areas is assured for the majority of the population, whereas in developing countries, the situation is more varied, as these countries face diverse challenges, including quality of service. Although in South Africa, public transport claims a significant portion of, and is a substantial contributor to, the country's gross domestic product (GDP), this industry is unfortunately overlooked as regards the calculation of the transport sector's contribution to both the GDP and other social and developmental objectives of the country, including, job creation (Ndebele 2011). For example, the South African taxi industry is estimated to contribute more than R30 billion to the country's GDP (Ndebele 2011). More specifically, the Johannesburg metropole has 800000 daily commuters $-39.6 \%$ use minibus taxis, $27.1 \%$ use private cars, $24.1 \%$ use buses and 9.2\% use trains (Ndebele 2011).

Public transport is generally used by the poorer members of the community (Finn \& Mulley 2011; Mashiri, Moeketsi \& Baloyi 2010), despite inefficiencies (Thomas, Ryneveld \& Pascarel 2010). Bus commuters are often faced with inadequate service, poorly arranged schedules, lack of facilities, including bus stops and shelters, and infrequency of services, particularly at off-peak times, thus the convenience of these services is severely compromised (Mashiri et al. 2010).

Service quality in the public transport sector in South Africa has remained an elusive and a much neglected area of study, and data regarding quality and performance indicators of public transportation services are vaguely determined and, in fact, practically non-existent. Furthermore, Javid et al. (2013), citing several researchers (Githui, Nakamura \& Okamuraet al. 2010; Joewono et al. 2010; Zhang et al. 2005), argue that only few studies in developing countries provide evidence of using structural equation modelling techniques to assess commuters' perceptions of service quality of public transportation modes, and to explore the factors responsible for their effectiveness. Moreover, the majority of the research to date has attempted to use the SERVQUAL methodology in an effort to measure service quality (Agyemang 2011; Githui et al. 2010; Randheer, Al-Motawa \& Vijay 2011; Sahney, Banwet \& Karunes 2004).

In light of the above, this paper reports on a study which used the methodology developed by McKnight, Pagano and Paaswell (1986) to measure service quality in the public bus sector, using the dimensions reliability, extent of service, comfort, safety and affordability (RECSA), and to determine the importance of each service quality dimension. These dimensions and the items which characterise each service quality dimension are depicted in Figure 1.

\section{Brief literature review}

Public transport faces severe problems in almost all countries of the developing world, although the situation varies from one country to another and even from one city to another (Vasconcellos 2001, as cited by Pucher \& Korattyswaroopam 2004). Over the last few years, the public transport industry in many countries, especially developing countries, has been involved in a process of transformation (Randheer et al. 2011). 


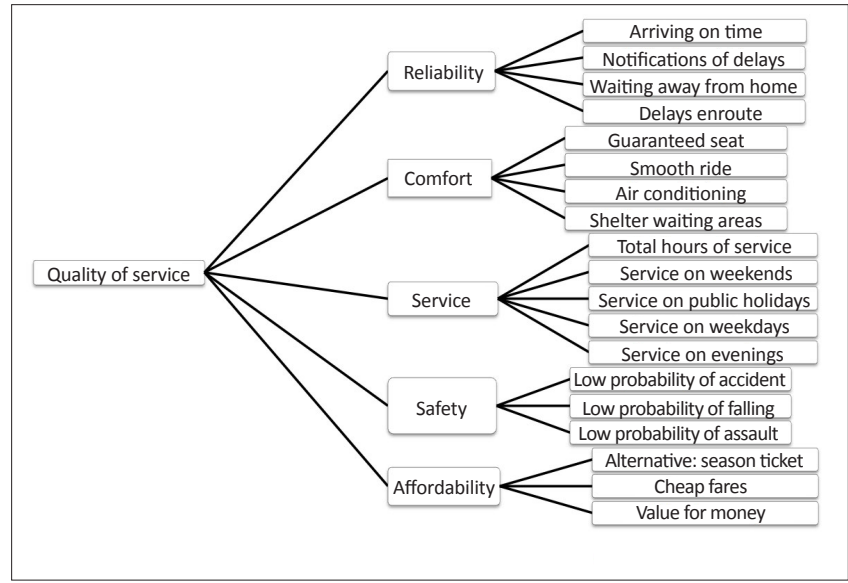

Source: McKnight, C.E., Pagano, A.N. \& Paaswell, R.E., 1986, 'Using quality to predict demand for special transportation', in Behavioural Research for Transport Policy, Proceedings of the International Conference on Travel Behaviour, Noordwijk, The Netherlands, VNU Science Press, Utrecht

FIGURE 1: Service quality dimensions.

In South Africa, developments in the transportation industry have been less than satisfactory. The focus has not been on providing quality service and, as a result, commuter satisfaction has been curtailed in at least two ways (Barnes 1989):

- The attention of transport operators has been distracted from the primary objective of providing efficient service and more focused on operational efficiency in order to maximise profitability.

- Insufficient attention has been paid to addressing passenger needs, as this was perceived as a 'nice to have' instead of something requiring major attention.

The National Household Travel Survey (2003) revealed that $71 \%$ of train users, $55 \%$ of taxi users and $54 \%$ of bus commuters were dissatisfied with the level of crowding (Gauteng Province 2009). In addition, 74\% of bus commuters, $64 \%$ of taxi users and $53 \%$ of train users were unhappy with the facilities at stops, ranks and stations. There has also been severe overcrowding on all modes of public transport, primarily as a result of there not being sufficient vehicles and coaches available as well as a lack of choice. In addition, there are excessive delays, with an average waiting time of 40-65 min (Gauteng Province 2009).

Several researchers (Beirao \& Cabral 2007; Fillone, Montalbo \& Tiglao 2005; Mazulla \& Eboli 2006) maintain that one of the challenges that transport organisations face is that service quality is a complex area of study and measuring service quality, particularly in public transport, is complicated by the subjective nature of the service. Furthermore, whilst instruments have been developed to assist organisations in measuring service quality in order to meet the needs of commuters, there has, in the main, been no agreement on the measurement of the concept. In the absence of objective measures, a useful and appropriate approach to assessing the quality of an organisation's services would be to measure the customers' perceptions of quality (Thompson, De Souza \& Gale 1985). In light of the aforementioned, this paper aims to explore commuters' perceptions of bus and minibus taxi services in terms of McKnight et al.'s (1986) service quality dimensions, namely reliability, extent of service, comfort, safety and affordability (RECSA), and to recommend strategies to improve public bus transport service quality based on the research findings.

\section{Research strategy Research procedure and sampling}

Due to the complexities of sampling in public transport, choosing a probability sample is always a challenge. Often area sampling, also referred to as the geographical sampling technique, a form of cluster sampling, is used in studies where there are visible problems of unavailability of a practical sampling frame for individual elements (Cooper \& Schindler 2001). Area sampling techniques were used to select terminals in Johannesburg, thereby intercepting passengers to be included in the study.

One challenge to selecting a sample of bus commuters to participate in the research was that no sample frame of city public transport commuters exists, according to Cooper and Schindler (2001). According to the same authors, regular bus commuters use monthly passes, and infrequent commuters usually pay their fares in cash, which makes choosing a sample frame very challenging. One sample frame available to bridge the gap, which was not considered by these researchers, was a list of bus routes which would have allowed the researchers to draw a probability sample using the cluster sampling technique. However, the challenge was obtaining the bus routes as the bus operators were unwilling to supply the list of routes. To overcome this challenge, the selection of bus terminals using a map and choosing a sample from the list of bus terminals concerned was more realistic and acceptable (Cooper \& Schindler 2001).

The sample was selected using the following procedure, taking into consideration costs, speed of data collection and the availability of the population elements, amongst others:

- A letter was sent to the City of Johannesburg Transport and Planning Department requesting detailed maps of Johannesburg's public bus terminals. These maps were scrutinised for accuracy to ascertain whether they highlighted all the bus terminals in Johannesburg. This process validated the maps, which were then utilised in the sampling process.

- Geographical sampling was used, in terms of which bus terminals were grouped into homogeneous clusters. For example, terminals in townships were grouped together, terminals in suburban areas were grouped together, and terminals in the CBD were grouped together to ensure the homogeneity of the subjects in each cluster (Cooper \& Schindler 2001).

As, according to Forsyth and Smyth (1986), on-bus and terminal interviews achieve a higher response rate than conventional surveys, and personal interviews and on-bus or terminal distribution aid the willingness to participate, a 'commuter intercept survey' was used for data collection. Face-to-face interviews were conducted by a trained 
researcher (fieldworker). The interviews were conducted until a random sample of 200 commuters were interviewed during an entire week (Monday to Sunday) at bus terminals in central Johannesburg in order to ensure that a fair representation of all types of commuters could be surveyed.

As one of the strengths of quantitative research is that it facilitates exploring causality amongst related variables and thus helps in building models that illustrate the strength and direction of related variables (Cooper \& Schindler 2001), this study used mainly quantitative research, which is associated with a structured research process where data is collected and analysed.

\section{Research instrument}

Beirao and Cabral (2007) and several other researchers argue that the measurement of service quality in the transport sector remains a challenging and important research area, and a major contributing factor is the lack of accurate measurement instruments. Previous studies, such as the one by Githui et al. (2010) which investigated public transport service attributes that influence overall passenger satisfaction and ultimately enhancing public transportation use in developing countries such as Kenya, used a specifically designed questionnaire comprising 25 items which defined the dimensions of reliability, safety, comfort, affordability and availability of service.

For the purposes of this study, a specifically designed questionnaire was used to collect data. This questionnaire addressed the service attributes clustered under each of the five service quality dimensions depicted in Figure 1, as well questions regarding the importance of each of the service quality dimensions, and biographic and other relevant data which addressed the objectives of the study. A five-point Likert scale was used to measure the commuters' perceptions of service quality as measured by the various items which comprised the five transport service quality dimensions.

The following is an example of a question which addressed reliability:

Do you have easy access to public bus timetables?

Strongly agree $\frac{}{5} \frac{}{4} \frac{1}{3} \frac{}{2} \frac{1}{1}$ Strongly disagree

Pre-testing was conducted in order to ensure that the measuring instrument met the objectives of the study in terms of the information to be collected (Aaker, Kumar \& Day 2007). The pilot study was conducted by randomly selecting and interviewing 27 commuters. Initially, the interviewing process lasted about $20 \mathrm{~min}$. However, after some questions were reworded, the process was reduced to about $15 \mathrm{~min}$.

\section{Data analysis}

The Statistical Package for the Social Sciences (SPSS) Version 11.0 for Windows (Coakes \& Steed 2003), a widely used package in advanced statistical analysis, was used to analyse the data. The following factors influenced the selection of the most appropriate technique for the purposes of data analysis: type of data, research design, assumptions underlying the test statistic and related considerations (Aaker et al. 2007).

\section{Findings Reliability and validity}

Reliability concerns the precision of the measurement procedure. According to Coakes and Steed (2003:140), although there are a number of different reliability coefficients, one of the most commonly used is Cronbach's alpha, in that similar results will be obtained if the survey is conducted amongst a larger sample of respondents. The service quality dimensions were assessed individually for reliability using the Cronbach's alpha measures, and the following coefficients were produced: reliability 0.767 ; service 0.734 ; comfort 0.712 ; safety 0.734 and affordability 0.789 . These indicate that the five service quality dimensions were fairly reliable as the Cronbach's alpha values exceeded 0.6, which according to Byrne (2010) is an acceptable reliability value.

Several aspects of validity are pertinent within the ambit of research instrument validity assessment. However, as the research instruments were adapted from previous studies where they were validated, only face validity was considered in this study. Face validity simply means that researchers are taking the validity at face value by looking at whether an instrument (questionnaire) appears to measure the target variable (Cronbach \& Meehl 1955). For example, the instrument intended to measure the commuters' perceptions of service quality comprised the items related to the five (RECSA) dimensions. On the basis of the pilot study, it was established that the questionnaire had face, construct and content validity, in that the questions measured exactly what they were intended to measure, and examined the relationship between commuters' perception of service and the service quality dimensions, and that the measure adequately covered the content area (Miller 2012). At face value, these questions definitely measure service quality as perceived by commuters and, combined with the fact that they are also adapted from previous studies (McKnight et al. 1986) that measure service quality, the face validity of the RECSA instrument used was assured.

\section{Factor analysis}

Factor analysis can help detect underlying sets of subconstructs and identify which questions are contributing to the variation in the dataset and could be potentially latent variables. In this study, factor analysis was used as a tool to identify suitable dimensions and related items (Randheer et al. 2011) and analyse the underlying factors in service quality for public transport. Factor analysis was conducted using the principal components method with varimax rotation to determine the validity of the items comprising the questionnaire developed to measure the relationship amongst the variables whose relationship in the conceptual 
model is being investigated (Johnson \& Wichern 2007). Factor analysis was conducted using the following steps:

- The number of factors was determined. This was done through the scree plot (Appendix 1), a plot of the eigenvalues against the number of factors, in order of extraction, and the eigenvalues of the correlation matrix. An eigenvalue represents the amount of variance in the original variables that is associated with a factor (Aaker et al. 2007). According to the same authors, a factor with an eigenvalue of less than 1.0 is no better than a single variable, as, due to standardisation, each variable has a variance of 1.0. Thus, in this study, only principal components with eigenvalues greater than 1 were retained.

- Varimax rotation was performed in order to make the factor loadings more meaningful.

- The significance test was considered to determine the statistical significance of the separate eigenvalues in order to retain only those factors that are statistically significant.
- To determine which variables are related to their respective factors, loadings greater than 0.40 was taken into account. All factor loadings and correlations are expressed as a percentage. In some cases, items can be excluded if the loadings are small across all factors.

The results of the exploratory factor analysis which was performed on all the scale items - namely reliability, comfort, service (or extent of service), safety and affordability - using the principal component analysis method (as the method of estimation) and varimax rotation with Kaiser normalisation are reflected in Table 1.

It is evident from Table 1 that only three factors, namely punctuality, timetables and timely arrival at destination, explained $78.943 \%$ of the cumulative variance amongst the factors. The next step entailed examining the rotated loadings table to determine which questions were not loading at all on the factors and could hence be eliminated from the dataset, and then the factor analysis process was re-run. The output of the aforementioned procedure is reflected in Table 2.

TABLE 1: Results of factor analysis.

\begin{tabular}{|c|c|c|c|c|c|c|c|c|c|}
\hline \multirow[t]{2}{*}{ Component } & \multicolumn{3}{|c|}{ Initial eigenvalues } & \multicolumn{3}{|c|}{ Extraction sums of squared loadings } & \multicolumn{3}{|c|}{ Rotation sums of squared loadings } \\
\hline & Total & $\%$ of variance & Cumulative $\%$ & Total & $\%$ of variance & Cumulative $\%$ & Total & $\%$ of variance & Cumulative $\%$ \\
\hline 1 & 26.801 & 70.528 & 70.528 & 26.801 & 70.528 & 70.528 & 12.340 & 32.473 & 32.473 \\
\hline 2 & 1.930 & 5.079 & 75.607 & 1.930 & 5.079 & 75.607 & 9.632 & 25.347 & 57.821 \\
\hline 3 & 1.268 & 3.336 & 78.943 & 1.268 & 3.336 & 78.943 & 8.026 & 21.122 & 78.943 \\
\hline 4 & 0.955 & 2.513 & 81.456 & - & - & - & - & - & - \\
\hline 5 & 0.804 & 2.115 & 83.571 & - & - & - & - & - & - \\
\hline 6 & 0.590 & 1.554 & 85.125 & - & - & - & - & - & - \\
\hline 7 & 0.505 & 1.328 & 86.454 & - & - & - & - & - & - \\
\hline 8 & 0.452 & 1.191 & 87.644 & - & - & - & - & - & - \\
\hline 9 & 0.394 & 1.038 & 88.682 & - & - & - & - & - & - \\
\hline 10 & 0.340 & 0.894 & 89.577 & - & - & - & - & - & - \\
\hline 11 & 0.329 & 0.867 & 90.443 & - & - & - & - & - & - \\
\hline 12 & 0.282 & 0.741 & 91.185 & - & - & - & - & - & - \\
\hline 13 & 0.259 & 0.682 & 91.866 & - & - & - & - & - & - \\
\hline 14 & 0.243 & 0.639 & 92.506 & - & - & - & - & - & - \\
\hline 15 & 0.223 & 0.587 & 93.093 & - & - & - & - & - & - \\
\hline 16 & 0.217 & 0.572 & 93.664 & - & - & - & - & - & - \\
\hline 17 & 0.209 & 0.549 & 94.214 & - & - & - & - & - & - \\
\hline 18 & 0.191 & 0.503 & 94.717 & - & - & - & - & - & - \\
\hline 19 & 0.173 & 0.454 & 95.171 & - & - & - & - & - & - \\
\hline 20 & 0.161 & 0.423 & 95.594 & - & - & - & - & - & - \\
\hline 21 & 0.151 & 0.396 & 95.990 & - & - & - & - & - & - \\
\hline 22 & 0.134 & 0.353 & 96.343 & - & - & - & - & - & - \\
\hline 23 & 0.133 & 0.349 & 96.693 & - & - & - & - & - & - \\
\hline 24 & 0.124 & 0.327 & 97.019 & - & - & - & - & - & - \\
\hline 25 & 0.122 & 0.320 & 97.339 & - & - & - & - & - & - \\
\hline 26 & 0.116 & 0.305 & 97.644 & - & - & - & - & - & - \\
\hline 27 & 0.103 & 0.272 & 97.916 & - & - & - & - & - & - \\
\hline 28 & 0.099 & 0.259 & 98.176 & - & - & - & - & - & - \\
\hline 29 & 0.097 & 0.256 & 98.431 & - & - & - & - & - & - \\
\hline 30 & 0.091 & 0.239 & 98.670 & - & - & - & - & - & - \\
\hline 31 & 0.084 & 0.222 & 98.892 & - & - & - & - & - & - \\
\hline 32 & 0.077 & 0.201 & 99.093 & - & - & - & - & - & - \\
\hline 33 & 0.073 & 0.192 & 99.286 & - & - & - & - & - & - \\
\hline 34 & 0.071 & 0.187 & 99.473 & - & - & - & - & - & - \\
\hline 35 & 0.059 & 0.156 & 99.629 & - & - & - & - & - & - \\
\hline 36 & 0.054 & 0.141 & 99.770 & - & - & - & - & - & - \\
\hline 37 & 0.046 & 0.121 & 99.891 & - & - & - & - & - & - \\
\hline 38 & 0.041 & 0.109 & 100.000 & - & - & - & - & - & - \\
\hline
\end{tabular}


Most literature suggests that a factor loading of 0.3 or greater can be considered to be significant (Kline 1994). However, given the large number of items in the scale, factor loadings of 0.4 or higher were considered to be significant, otherwise the number of items in the dataset would not have been reduced, and the very purpose of factor analysis, namely to reduce the number of items to a comprehensible set of items, would have been defeated. Based on the rotated component matrix reflected in Table 2, it is evident that none of the questions have loadings of less than 0.4 and therefore no questions were dropped.

In this case the model selected the following underlying factors: punctuality of buses, bus timetables, timely arrival of buses at destination, failure of buses to arrive on time. In total, $78.94 \%$ of the variation in the data may be explained by the first three principal components. Factor 1 is heavily loaded on the importance of using public bus transport in the future as regards to safety, availability, comfort and affordability. Factor 2 is heavily loaded on the combination of comfort and timely arrival at destination. Factor 3 is heavily loaded on the extent of service (or availability).

\section{Biographical data}

With respect to the gender of the respondents in terms of their use of public buses, it was ascertained that the majority $(67.0 \%)$ of male respondents used public buses 'more often' than their female counterparts. It also became evident that only $29.8 \%$ of the respondents used public buses, whilst the vast majority $(70.2 \%)$ indicated minibus taxis as preferred mode of transportation. It was also apparent that whilst the vast majority (98.0\%) of the youth used public transport, only $36.0 \%$ of this group utilised the public bus service.

\section{Importance of the service quality dimensions and evaluation of public bus service quality}

Table 3 below presents the summary statistics in respect of the importance attached to each of the five dimensions of quality of service, on a scale of 1 (less important) to 5 (very important). It shows that all five service quality dimensions are considered very important, and equally so.

Structural equation modelling (SEM) was used to determine whether the conceptual model (Figure 1) is valid, as it allows for multiple measures to be associated with a single latent construct, as reflected in Figure 1. Before any SEM was done, the data had to be manipulated as the variables (service quality dimensions) comprised several items. The average of items was used to create a unidimensional variable for transport service quality.

Two models were fitted to the data. One was a latent variable model (Figure 1) which did not fit the data well and is not commented on any further. The other model (Figure 2), which fitted the data well, was the appropriate model. As shown in Figure 2, one of the RECSA service quality dimensions, namely affordability, was not found to be contributing to the
TABLE 2: Rotated component matrix.

\begin{tabular}{|c|c|c|c|}
\hline \multirow[t]{2}{*}{ Component } & \multicolumn{3}{|c|}{ Components } \\
\hline & 1 & 2 & 3 \\
\hline Importance of bus service & 0.882 & 0.188 & 0.299 \\
\hline Importance of affordability of service & 0.867 & 0.214 & 0.294 \\
\hline Importance of service buses & 0.861 & 0.217 & 0.291 \\
\hline Importance of comfort & 0.841 & 0.231 & 0.313 \\
\hline Importance of reliability & 0.787 & 0.348 & 0.300 \\
\hline Affordability and future utilisation intention & 0.714 & 0.421 & 0.333 \\
\hline Safety and future utilisation intention & 0.689 & 0.450 & 0.340 \\
\hline Drivers obeying the rules of the road & 0.682 & 0.460 & 0.307 \\
\hline Drivers' driving skills & 0.677 & 0.507 & 0.303 \\
\hline Fares are affordable & 0.656 & 0.450 & 0.322 \\
\hline Fares are fair & 0.646 & 0.515 & 0.337 \\
\hline Fares are worth it & 0.642 & 0.462 & 0.342 \\
\hline Availability and future utilisation & 0.633 & 0.459 & 0.391 \\
\hline Value-for-money service & 0.617 & 0.521 & 0.315 \\
\hline Injuries due to accidents & 0.609 & 0.522 & 0.353 \\
\hline Knowledge of exact location and destination & 0.578 & 0.505 & 0.361 \\
\hline Comfort and future utilisation possibility & 0.576 & 0.514 & 0.412 \\
\hline Availability on weekdays & 0.563 & 0.418 & 0.449 \\
\hline Friendliness of drivers & 0.533 & 0.483 & 0.468 \\
\hline Arrival at destination & 0.458 & 0.742 & 0.304 \\
\hline Timely arrival at destination & 0.460 & 0.735 & 0.323 \\
\hline Air-conditioned & 0.316 & 0.722 & 0.429 \\
\hline Smoothness of ride & 0.455 & 0.715 & 0.330 \\
\hline Ease of finding a seat & 0.470 & 0.707 & 0.267 \\
\hline Punctuality & 0.454 & 0.667 & 0.388 \\
\hline Feelings about lack of air-conditioners & 0.012 & 0.643 & 0.371 \\
\hline Reliability for future use & 0.490 & 0.639 & 0.344 \\
\hline Failure to be on time & 0.335 & 0.619 & 0.537 \\
\hline Adherence to routes & 0.541 & 0.592 & 0.258 \\
\hline Condition of buses & 0.534 & 0.588 & 0.392 \\
\hline Availability in holidays & 0.342 & 0.363 & 0.819 \\
\hline Rate of accidents & 0.347 & 0.282 & 0.815 \\
\hline Availability in the evenings & 0.348 & 0.342 & 0.813 \\
\hline Availability on weekends & 0.391 & 0.330 & 0.756 \\
\hline Bus fares & 0.399 & 0.253 & 0.732 \\
\hline Often use buses & 0.282 & 0.390 & 0.729 \\
\hline Bus timetable & 0.307 & 0.510 & 0.623 \\
\hline Condition of bus shelters & 0.475 & 0.485 & 0.486 \\
\hline
\end{tabular}

Note: Rotation converged in six iterations.

TABLE 3: Importance of service quality dimensions.

\begin{tabular}{lcc}
\hline Service quality dimensions & Mean & Median \\
\hline Reliability & 4.3 & 5.0 \\
Comfort & 4.4 & 5.0 \\
Service & 4.3 & 5.0 \\
Safety & 4.3 & 5.0 \\
Affordability & 4.4 & 5.0 \\
\hline
\end{tabular}

fit of the model and may have been a suppressor variable. Therefore it had to be dropped as it would have also affected the fit of the model to the data.

Several goodness-of-fit statistics that are standard analysis of moment structures (AMOS) outputs, namely chi-square, relative fit index (RFI), root mean square error of approximation (RMSEA) and incremental fit index (IFI), were considered, as most of these are interrelated and lead to the same conclusion regarding the fit of the model to the sample data (Byrne 2010:75-80). The RFI should be close to 0.95 if the model fits the data well. The RMSEA should be less than 0.05 and have a 
$p$-value greater than 0.05 based on a narrow confidence interval from the RMSEA (referred to as PCLOSE in the AMOS output) to indicate superior fit of the model. The IFI, which addresses issues of parsimony and sample size of the model relative to the data and which according to Byrne (2010:79) is also a measure of the goodness of fit, should be close to or more than 0.95 if adequate model fit is to be achieved.

The fitted model (Figure 2) had a chi-square test statistic of 0.032 with a $p$-value of 0.876 , which is non-significant at the $5 \%$ level, implying that the revised conceptual model (Figure 2) fitted to the research data was indeed a good one (Byrne 2010:76). Furthermore, the RFI was 0.981, the RMSEA was 0.0085 with a $p$-value (PCLOSE) of 0.897 and the IFI was 0.969, all confirming a good fit of the model (Byrne 2010).

On the basis of the regression weights (Table 4), it is evident that the reliability, comfort, service and safety significantly (5\% level of significance) influence the overall service quality of public buses. It is also interesting to note that the comfort and service have negative coefficient estimates, whilst reliability and safety have positive coefficients.

The multiple regression model discussed above would not be sufficient in isolation in the current scientific setting. By fitting a model with overall service quality as the response variable and the demographic variables age, gender, income and so forth as the explanatory variables, it was decided to also utilise the generalised linear model with a uniform link and a normal distribution, as the explanatory variables are neither continuous nor normally distributed but categorical. In the multiple regression model this would require the

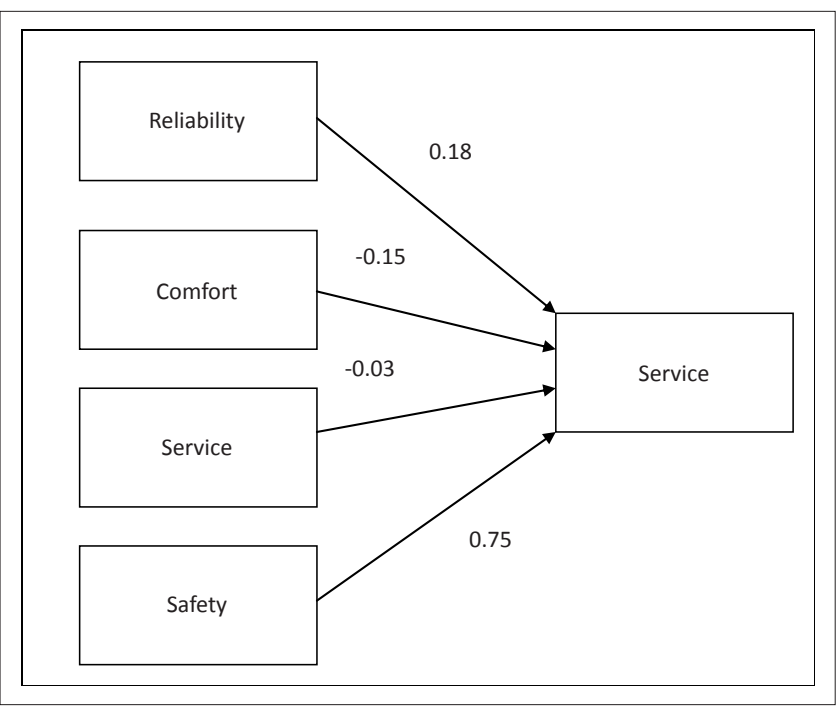

Source: Authors' own construction

FIGURE 2: Revised conceptual public bus service quality model. use of dummy variables, which would become bulky and tedious. In view of the aforementioned, the generalised linear regression model was also considered. As the average of several variables was taken into account to calculate overall service quality, the response variable would be normally distributed. The fitted model was:

Overall service quality is:

$\beta_{0}+\beta_{1}{ }^{*}$ age $+\beta_{2}{ }^{*}$ gender $+\beta_{3}{ }^{*}$ occupation $+\beta_{4}{ }^{*}$ education $+\beta_{5}$ $*$ income $+\varepsilon$

[Eqn 1]

It is evident from the type III test results reflected in Table 5 that age, education and income were all significant (at the $5 \%$ level) in influencing the overall service quality, as their $p$-values are all less than 0.05 . However, gender and occupation were not significant in influencing commuters' perception of the overall service quality provided by the buses.

\section{Discussion of findings and conclusion}

The factor analysis process revealed that Factor 1, which may be explained as 'the comfort of service', is important as it affects passengers' perception of the service. This was confirmed by the SEM output, which showed comfort as significantly influencing commuters' perception of the overall service quality that the public buses provided.

Increased comfortmay alsoimprovehealth, the environmental situation on board in terms of the conditions, as well as productivity at the workplace (Lovelock, Lewin, Bateson \& John 1987). When deciding which mode of transport to use, passengers tend to take comfort into account, according to Samson and Thompson (2007). Budiono (2009) also found that comfort of service was one of the top four factors that positively correlated with overall service satisfaction. Service comfort involves the availability of service aesthetics, which include the availability of seats and space (often referred to as passenger density), smooth journeys, the availability of airconditioners and the condition of the shelters (Litman 2008). Seat availability should be displayed on public transport vehicles, on the electronic information boards at bus ranks, and at bus stops. The load factor, which is the percentage of a vehicle's total capacity that is actually occupied, may play an important role in controlling the seat availability by ensuring that vehicles are not uncomfortably full (City of Johannesburg 2012). The Bus Rapid Transport (BRT) Rea Vaya system operates on a load factor ranging between $70 \%$ and $80 \%$ during peak periods in order to avoid overcrowding and to increase comfort (Rea Vaya 2011), whilst in the Bogotá

TABLE 4: Regression weights - public bus services.

\begin{tabular}{lllll}
\hline Service quality & Estimate & Standard error & Critical ratio & Probability \\
\hline Reliability & 0.181 & 0.017 & 10.569 & 0.000 \\
Comfort & -0.146 & 0.018 & -7.977 & 0.000 \\
Extent of service & -0.035 & 0.015 & -2.269 & 0.023 \\
Safety & 0.745 & 0.019 & 39.949 & 0.000 \\
\hline
\end{tabular}


TABLE 5: Tests of model effects.

\begin{tabular}{lccc}
\hline Model & \multicolumn{3}{c}{ Dependent variable } \\
\cline { 2 - 4 } & Wald chi-square & $\boldsymbol{d f}$ & Significance \\
\hline (Intercept) & 851.160 & 1 & 0.000 \\
Age & 15.725 & 4 & 0.003 \\
Gender & 0.428 & 1 & 0.513 \\
Occupation & 9.790 & 6 & 0.134 \\
Education & 34.957 & 5 & 0.000 \\
Income & 21.798 & 6 & 0.001 \\
\hline
\end{tabular}

$d f$, degrees of freedom

Trans Milenio system, typical load factors are $80 \%$ for peak periods and 70\% for non-peak periods (City of Johannesburg 2012). Although a 100\% load factor would be the ideal for operational viability, the sometimes long 'wait' to reach this capacity and the tendency to 'overload' buses can contribute to service dissatisfaction (and discomfort) amongst commuters. Nevertheless, if a $100 \%$ load factor could be achieved by taking cognisance of the 'long wait' and overloading of buses, then this should be targeted by the bus operators.

With respect to the reliability of the service, there is need to implement more and better information and communication technology (ICT) systems, which will improve communication with passengers. Some ICT systems include timetables, internet messaging, smart messaging systems, terminal electronic displays, on-board communication, mobile communications and call centres. The specific benefits of most of the ICT solutions, apart from them being a channel through which information may be shared, include increased operational efficiency, lower costs of transacting, and increased productivity amongst internal employees, all of which may translate into enhancing positive perceptions of service.

Another important factor that may influence the perception of the quality of bus transport is the availability of timetables. Researchers such as Chakwizira et al. (2011) have shown that timetables are important, and a lack thereof may be construed as breaking the trust between the operator and passengers. As timely arrival at the destination was also considered an important factor, public bus transport service providers should take into account the arrival times of vehicles at their destination. In an attempt to develop a service quality index, Hensher, Stoper and Bullock (2003) established that journey length is often the main cause of commuter dissatisfaction. If public transport service providers are not able to reduce the travelling distances between departure and destination, they should at least consider ensuring that the vehicles are comfortable as this would improve the conditions inside the vehicles and minimise passenger fatigue.

In the main, the extent of the service pertains to taking passengers directly to their location with no transfers involved; the availability of service during the day (peak and off-peak), in the evenings, over weekends, and on public holidays; and driver friendliness. In order to address the problem of integration and optimisation, the BRT Rea Vaya was designed (City of Johannesburg 2012). Similar initiatives were introduced or are in the process of being introduced in other developing countries such Ghana (Accra), Tanzania (Dar es Salaam), India (Delhi) and Mauritius (Finn \& Mulley 2011). However, as long as passengers are required to transfer from one mode to another in order to reach their final destinations, the efficiency of the system will remain an elusive dream. Furthermore, the attempted integration of the BRT with other modes of transport is still a work in progress. The findings imply that public bus service providers need to be cognisant of the importance of these 'influencers' of service quality and should devise and implement strategies to improve the overall quality of the service.

\section{Recommendations}

Considering that all elements of the RECSA model were not applicable to the sample, and that the proposed model had to be revised to fit the data, it may be necessary to probe the underlying reasons and conduct further studies before widespread generalisations could be made on the basis of the findings of this study. Furthermore, contrary to what is documented in the literature, affordability did not seem to affect bus commuters' perception of the overall transport service equality. Thus, further research using a large sample of bus commuters is required to uphold or challenge the findings.

The developed structural models can be used to evaluate commuters' satisfaction with and preferences regarding other public transportation modes, namely minibus and train services. This study would help transport planners to take the necessary steps for improving wagon service quality.

It is essential that public transport service providers focus on improving punctuality, ensuring timely arrival at destinations, taking passengers to their exact destinations, providing reasons for the failure to arrive at destination on time, and availability of timetables. However, this requires efficient planning and scheduling systems that are, in turn, capable of addressing and minimising the impact of service interruptions. Thus, the planning system should improve both operational efficiencies and predictability of the service whilst also being flexible and reliable.

A bus timetable should be more readily available and accessible to a large number of commuters. In addition, the introduction of effective communication channels should also be considered. The content of such communication should include, at the very least, departure and arrival times, route maps, fares, comfort ratings and general customer service information, including the call centre number and the operator's pledge to the service charter.

There is also a need to improve the aesthetics of public transport vehicles. The availability of seats should be communicated via electronic boards at bus shelters and ranks as well as at designated public transport stops. This 
information should also be accessible via smart messaging systems and the website. In addition, the information should be available in real time. Furthermore, the load factor, if implemented as recommended, would minimise passenger discomfort; therefore passenger counting systems should be mandatory on public transport in order to enforce the load factor.

It is recommended that public transport operators focus diligently on improving the comfort of their service offering, especially if public transport is to compete effectively with private motor vehicles. The introduction of a mandatory comfort rating for public transport may go a long way in addressing the issue of comfort in public transport. However, such a rating would need to be enforced by the law enforcement agencies.

Improving the condition of public transport infrastructure may also improve the perception of service. However, if the public transport infrastructure is neglected, the possibility that commuters will eventually become dissatisfied, increases. It is thus essential that an integrated public transport infrastructure programme be developed.

Public transport networks should be efficient. However, ongoing research and proper consultation with both the commuters and other stakeholders should be prioritised before the network is expanded in order to ensure that the needs of the commuters are matched with the needs of the public transport service providers.

\section{Limitations of the study}

This study was conducted in Johannesburg and did not extend to the other provinces, mainly because of the high costs of data collection. However, the sample is representative of the public transport population and hence, it is possible to extrapolate the results of the study to other provinces in South Africa.

Several challenges were experienced during the interview process, such as buses arriving before interviews had been completed, resulting in incomplete questionnaires that eventually had to be excluded from the analysis. In addition, some passengers were unwilling to answer certain questions.

\section{Acknowledgements Competing interests}

The authors declare that they have no financial or personal relationship(s) which may have inappropriately influenced them in writing this article.

\section{Authors' contributions}

A.M.V. (University of KwaZulu-Natal) conducted the research as part of his doctoral studies under guidance of K.K.G. (University of KwaZulu-Natal), who served as his study supervisor. K.K.G. then developed the article.

\section{References}

Aaker, D.A., Kumar, V. \& Day G.S., 2007, Marketing research, Wiley, Hoboken.

Agyemang, I.W., 2011, 'Measurement of service quality of TROTORO as public transport in Ghana: A case study - the City of Kumasi', Paper delivered at the 32nd Annual Southern African Transport Conference, Pretoria, South Africa, 8-11 July.

Barnes, C., 1989, Successful marketing for the transport operator: A practical guide, Kogan Page, London.

Beirao, G. \& Cabral, J.S., 2007, 'Enhancing service quality in public transport systems', Transport Policy 14, 478-489.

Budiono, O.A., 2009, 'Customer satisfaction in public bus transport - A study of travelers' perception in Indonesia', Master's thesis, Service Science Programme, Karlstad University.

Byrne, B.M., 2010, Structural equation modeling with AMOS: Basic concepts, applications and programming, Routledge, New York.

Chakwizira, J., Bikam, P., Dayomi, M.A. \& Adeboyejo, T.A., 2011, 'Some missing dimensions of urban public transport in Africa: Insights and perspectives from South Africa', The Built and Human Environment Review 4(2), 56-84.

City of Johannesburg, 2012, Fast facts, Johannesburg Development Agency Publishing, Johannesburg, viewed 10 June 2012, from http://www.jda.org.za/fast-facts

Coakes, S. \& Steed, L., 2003, SPSS analysis without anguish: Version 11.0 for Windows, pp. 135-145, Wiley, New York.

Cooper, R.D. \& Schindler, S.P., 2001, Business research methods, McGraw-Hill, Boston.

Cronbach, L.J. \& Meehl, P.E., 1955, 'Construct validity on psychological test', Psychological Bulletin 52, 281-302. http://dx.doi.org/10.1037/h0040957

Fillone, A.M., Montalbo, C.M. \& Tiglao, N.C., 2005, 'Assessing urban travel: A structural equations modeling (SEM) approach', Eastern Asia Society for Transportation Studies 5, 1050-2005.

Finn, B. \& Mulley, C., 2011, 'Urban bus services in developing countries and countries in transition: A framework for regulatory and institutional developments', Journa of Public Transportation 14(4), 89-107.

Forsyth, E. \& Smyth, A., 1986, 'Behavioural research on transport policy: The application of attitudinal research to the management of urban transport', Faculty of Environment, University of Leeds, Leeds.

Gauteng Province, 2009, Gauteng land transport framework, Department of Roads and Transport, Gauteng, viewed 20 September 2012, from http://www. roadsandtransport.gpg.gov.za/GLTF\%202009014\%20Final\%20Version\%201.\%20 August\%202011.pdf

Githui, J.N., Nakamura, F. \& Okamura, T., 2010, 'The structure of users' satisfaction on urban public transport service in developing country: The case of Nairobi', Journa of the Eastern Asia Society for Transportation Studies 8, 1288-1300, viewed 25 January 2014, from http://www.easts.info/publications/journal_proceedings/ journal2010/100237.pdf

Hensher, D.A., Stoper, P. \& Bullock, P., 2003, 'Service quality - Developing a service quality index in the provision of commercial bus contracts', Transportation Research, Part A: Policy and Practice 37(6), 499-517. http://dx.doi.org/10.1016/ S0965-8564(02)00075-7

Javid, M.A., Okamura, T., Nakamura, F. \& Wang, R., 2013, 'Comparison of commuters' satisfaction and preferences with public transport: A case of wagon service in Lahore', Jordan Journal of Civil Engineering 7(4), 426-472.

Johnson, R.A. \& Wichern, D.W., 2007, Applied multivariate statistical analysis, Prentice Hall, Upper Saddle River.

Kline, T., 1994, Psychological testing, Sage, London.

Litman, T., 2008, Valuing transit service quality improvements, Journal of Public Transportation 11(1), 43-64.

Lovelock, H.C., Lewin, G.D., Bateson, S.G. \& John, E.G., 1987, Marketing public transit: A strategic approach, Praeger, New York.

Mashiri, M.A.M., Moeketsi, P.N. \& Baloyi, V., 2010, Increasing public transport market share in South Africa: The options, Greater Pretoria Metropolitan Council, Public Passenger Transport Division \& Transportek, CSIR, Pretoria, viewed 20 Novembe 2010, from http://www.thredbo-conference-series.org/downloads/thredbo6 papers/Thredbo6-theme4-Mashiri-Moeketsi-Baloyi.pdf

Mazulla, G. \& Ebloi, L., 2006, 'A service quality experimental measure for public transport', European Transport 34, 42-53.

McKnight, C.E., Pagano, A.N. \& Paaswell, R.E., 1986, 'Using quality to predict demand for special transportation', in Behavioural Research for Transport Policy, Proceedings of the International Conference on Travel Behaviour, Noordwijk, The Netherlands, VNU Science Press, Utrecht.

Miller, M.J., 2012, Reliability and validity, lecture notes in Graduate Research Methods, Western International University, viewed 15 December 2013, from http://michaeljmillerphd.com/res500_lecturenotes/reliability_and_validity.pdf

National Household Travel Survey, 2003, Key results, pp. 1-29, Department of Transport, Pretoria.

Ndebele, S., 2011, Transportation in South Africa, Proceedings of the Transportation Investment Conference, Department of Transport Publishing, Cape Town.

Parasuraman, A., Zeithaml, V. \& Berry, L.L., 1988, 'SERVQUAL: A multiple-item scale for measuring customer perceptions of service quality', Journal of Retailing 64(1), $12-40$. 
Pucher, J. \& Korattyswaroopam, N., 2004, 'The crisis of public transport in India: Overwhelming needs but limited resources', Journal of Public Transportation 7(4), 1-20.

Randheer, K., Al-Motawa, A.A. \& Vijay, P.J., 2011, 'Measuring commuters' perception on service quality using SERVQUAL in public transportation', Internationa Journal of Marketing Studies 3(1), 21-34. http://dx.doi.org/10.5539/ijms. v3n1p21

Rea Vaya, 2011, Rea Vaya fact sheet, City of Johannesburg Department of Transport, viewed 22 July 2011, from http://www.reavaya.org.za/reava_factsheets
Sahney, S., Banwet, D.K. \& Karunes, S., 2004, 'A SERVQUAL and QFD approach to total quality education: A student perspective', International Journal of Productivity and Performance Management 53(2), 143-166. http://dx.doi. org/10.1108/17410400410515043

Samson, R. \& Thompson, P., 2007, Passenger focus, Free Post, Warrington.

Thomas, W., Ryneveld, V.P. \& Pascarel, N., 2010, Fact sheet, The BPO Learning Lab, University of Stellenbosch, Stellenbosch.

Thompson, P., De Souza, G. \& Gale, B.T., 1985, 'The strategic management of service quality', Pimsletter 33, The Strategic Planning Institute, Cambridge.

Appendix starts on next page $\rightarrow$ 


\section{APPENDIX}

Appendix 1: Scree plot of bus service quality factors

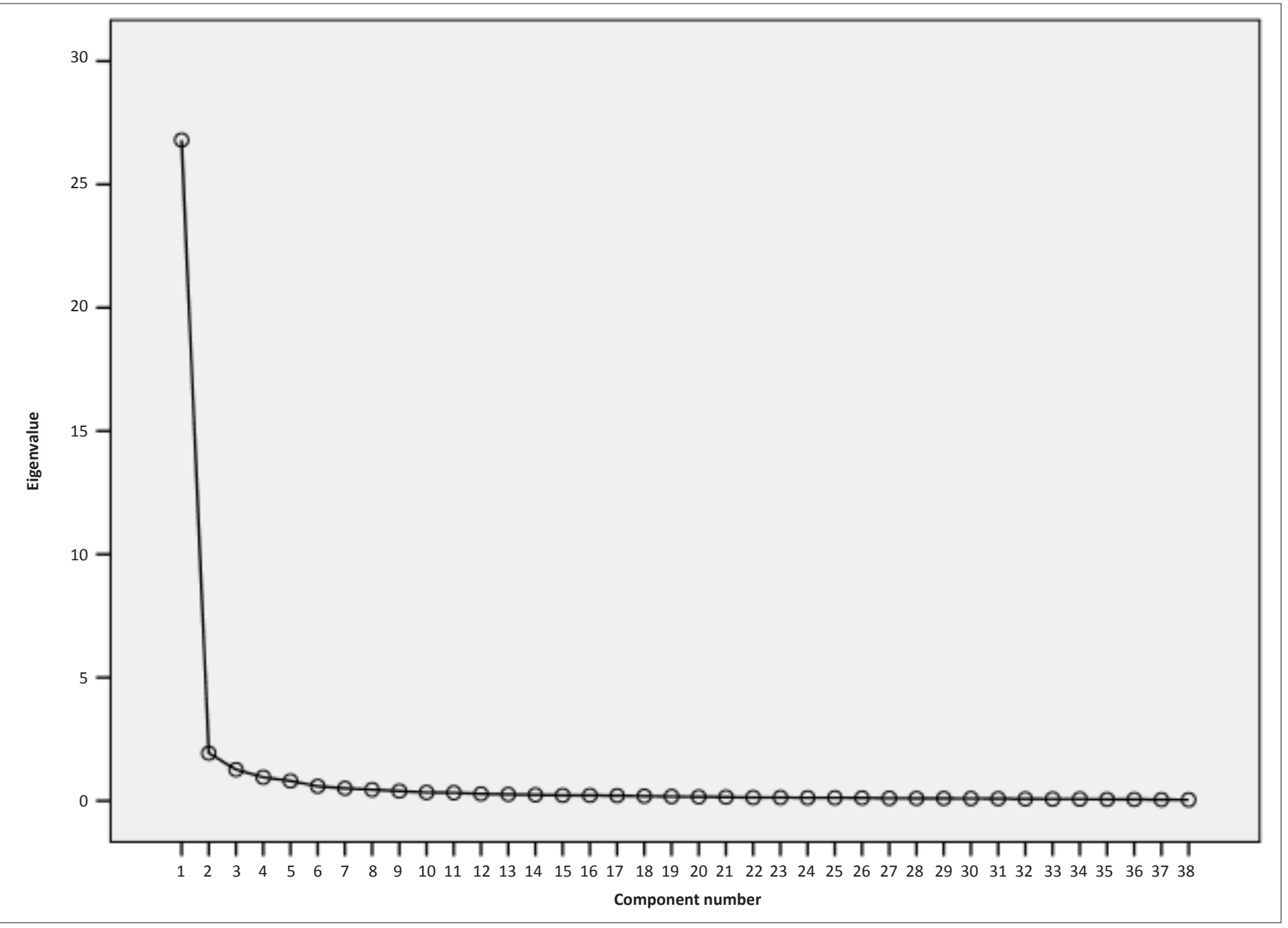

